\title{
A Method for Diagnosing Formation Fluid Leakage During the Operation of Sucker Rod Pumps and a Device for Its Implementation
}

\author{
Rzayev Abbas Heydar ${ }^{1}$, Asadova Rena Sharif ${ }^{1}$, Hagverdiyev Vugar Mamed ${ }^{2}$, \\ Gurbanov Zafar Gazanfar ${ }^{3}$ \\ ${ }^{1}$ Institute of Control Systems of the Azerbaijan National Academy of Sciences, Baku, Azerbaijan \\ ${ }^{2}$ Azerbaijan National Academy of Sciences, Baku, Azerbaijan \\ ${ }^{3}$ Baku Higher Oil School, Baku, Azerbaijan
}

Email address:

Abbas_r@mail.ru(R. A. Heydar), Renaasadova2007@rambler.ru(A. R. Sharif), zafer_adna@mail.ru(G. Z. Gazanfar), vugar.hagverdiyev@gmail.com (H. V. Mamed)

\section{To cite this article:}

Rzayev Abbas Heydar, Asadova Rena Sharif, Hagverdiyev Vugar Mamed, Gurbanov Zafar Gazanfar. A Method for Diagnosing Formation Fluid Leakage During the Operation of Sucker Rod Pumps and a Device for Its Implementation. American Journal of Energy Engineering. Vol. 8, No. 4, 2020, pp. 40-44. doi: 10.11648/j.ajee.20200804.12

Received: November 26, 2020; Accepted: December 14, 2020; Published: December 22, 2020

\begin{abstract}
The operation of oil sucker rod pumps (SRP) is known to be one of the most common and basic methods of oil production, especially for marginal wells. However, rapid wear of the plunger pair, tubing and sucker rods caused by friction, leading to a decline in equipment performance, as well as to labor intensity of replacement and repair of deep-well pumps, determines the relevance of developing methods for diagnosing the technical condition of sucker rod pumping units (SRPU) and formation fluid (FF) leakage during the operation of SRPU as an indicator of the technical condition of SRPU in particular. As one of the controlled parameters, leakage value is important for the operational control of well performance and increasing the efficiency of oil production. The authors consider the impacts of well product leakage both in the pump itself (the "cylinder-plunger" clearance, valves) and on the path of the pump product from the cylinder to the orifice (through threaded connections of the tubing string (TS) of the well, through possible pipe breakdowns caused by wear due to rubbing against the rods, etc.). In the existing literature, formulas are given for calculating the amount of fluid leakage through the clearance between the working surfaces of the plunger and the cylinder of a SRP during laminar flow in the clearance (laminar regime is the most probable), with the clearance as the main parameter, cubed. However, this formula requires determining the size of the clearance directly, which is an extremely difficult (impossible) task in an operating SRPU. And results of determining leakage from dynamometer cards and piezograms have low accuracy. In view of the above, the paper proposes a new method and a device for its implementation, which involves measuring the pressure on the well flow line and at two points of the tubing string (TS) of the well, one of which is located at the TS orifice, and the second lower at a distance of half the height of the cylinder of the pump being used, the FF leakage from downhole pumping equipment being calculated by the algorithms given in the text. It is shown that the proposed diagnostic method makes it possible to more accurately and reliably, in comparison with the existing methods, determine the formation fluid leakage during the operation of SRPU.
\end{abstract}

Keywords: Differential Pressure, Leakage, Sucker Rod Pump, Tubing, Flow Rate, Wells, Check Valve

\section{Introduction}

The operation of oil wells by sucker rod pumps is known to be one of the most common and basic methods of oil production, especially for marginal wells [1]. However, rapid wear of the plunger pair, tubing and sucker rods caused by friction, leading to a decline in equipment performance, as well as to labor intensity of replacement and repair of deepwell pumps, determines the relevance of developing methods for diagnosing the technical condition of sucker rod pumping units (SRPU) and fluid leakage during the operation of SRPU as an indicator of the technical condition of SRPU in 
particular. As one of the controlled parameters, leakage value is important for the operational control of well performance and increasing the efficiency of oil production.

There are known methods for determining leakage in SRP, which offer various solutions to this problem [2, 3]. leakage diagnostics is also carried out by building dynamometer cards [2] and piezograms [3].

The shortcoming of these methods is that they are quite cumbersome in implementation and allow obtaining only indirect values of diagnostic parameters based on a piezogram or a wattmeter card, using and conducting complex calculations that give a very large error.

Adonin proposed the following formula for calculating the amount of fluid leakage through the clearance between the working surfaces of the plunger and the cylinder of a SRP during laminar flow in the clearance (laminar regime is the most probable) [4]:

$$
q=0,016 g \frac{D_{p} H \delta^{3}}{v l}
$$

where $q$ is daily fluid leakage through the plunger-cylinder clearance, $\mathrm{m}^{3} /$ day; $g$ is gravitational acceleration, $\mathrm{m} / \mathrm{s}^{2} ; D_{p}$ is the pump diameter, $\mathrm{m} ; \delta$ is the side clearance, $\mathrm{m} ; H$ is the height of the pressure head created by the column of pumped fluid from the normalized dynamic level in the well to the wellhead, $\mathrm{m} ; \mathrm{v}$ is kinematic viscosity of pumped fluid, $\mathrm{cm}^{2} / \mathrm{s}$; $l$ is the contact length of the working surfaces of the cylinder and plunger, $\mathrm{m}$. It is shown that as the plunger pair wears out, the clearance increases and the leakage grows rapidly. However, this formula requires determining the size of the clearance directly, which is an extremely difficult (impossible) task.

We propose using the Hagen-Poiseuille formula to determine fluid leakage [5]:

$$
q=\frac{\pi D_{p} \Delta P}{12 \mu l} \delta^{3}
$$

where $\Delta P$ is the differential pressure at the ends of the plunger, $\mathrm{Pa} ; \mu$ is dynamic viscosity, $\mathrm{Pa} \bullet \mathrm{s}$.

It is shown that this formula is valid for the laminar regime of fluid flow in the clearance formed by two concentrically situated stationary cylindrical surfaces. According to the authors of [5], SRP delivery rate is most affected by leakage of the pumped fluid through the clearance in the pump's plunger pair.

B. B. Kruman established experimentally that leakage through the clearance of the plunger pair (PP) increases in proportion to the square of the pumping speed $\left(\vartheta^{2}\right)$, and the SRP delivery is proportional to this speed only in the first degree [6].

In [7-8], formulas are proposed for calculating the fluid flow rate in a pipeline based on the variable differential pressure, using a constriction device (diaphragm) installed in the pipeline [7] and a check valve installed on the flow line of an oil producing well [8], similar to formula (1) in this paper, without the empirical coefficient. However, those studies did not offer algorithms for estimating the value of the flow coefficient $\propto$, and the value of the fluid density $\rho_{f}$ is determined by laboratory methods. Moreover, a large error is allowed in representative sampling and analysis of the flow.

I. T. Mishenko considered the effect of well product leakage both in the pump itself (the "cylinder-plunger" clearance, valves) and on the path of the pump product from the cylinder to the orifice (through threaded connections of the TS, through possible pipe breakdowns caused by wear due to rubbing against the rods, etc.) [9]. It is shown that leakage during SRPU operation has a significant effect on the pump delivery; however, no algorithm is offered in this study for direct calculation of FF leakage.

The authors of $[5,10]$ propose a method to reduce fluid leakage through the clearance between the cylinder and the plunger of SRP. It is shown that the regular microrelief of the side holes [10] of the pump plunger helps reduce FF leakage through the clearance.

In [11], the variable factors influencing SRP delivery that change in time are analyzed, including:

1. leakage between the cylinder and the plunger, which depends on the degree of wear and the presence of abrasive impurities in the pumped fluid;

2. leakage in the pump valves due to their noninstantaneous closing and opening, mainly caused by wear and corrosion;

3. leakage through loose TS couplings, which are constantly subjected to alternating loads. It is shown that since leakage is directly proportional to the back pressure or pressure head height and inversely proportional to the length of the plunger, in practice it is necessary to increase the sealing surface by lengthening the plunger, i.e. the longer the plungers, the less leakage. When the plunger length is doubled, FF leakage is reduced by $50 \%$ [11]. However, this study, as well as the above-mentioned ones, does not offer an algorithm for direct estimation of the FF leakage during SRPU operation.

Rzayev et al presented a new method for determining the filtration characteristics of an oil reservoir, including well productivity, which allows determining FF leakage in well equipment indirectly [12]. Hence, it does not allow measuring the leakage values directly.

A number of studies are devoted to determining the FF flow rate with automated measuring the pressures at one point at the well head [13], at two points of at the head and on the flow line of the well [14], and at two points of the TS, one of which is located at the TS orifice, and the second one lower at a distance of half the height of the cylinder [15]. In these works, the corresponding calculation algorithms are proposed. However, the above works do not allow determining FF leakage during SRPU operation, since it requires measuring the pressure at three points, as our paper proposes.

\section{Problem Statement}

Development of a new method that allows to automatically determine FF leakage during the operation of SRPU more accurately and reliably in comparison with existing methods. It is necessary here to include in the mathematical expressions only the directly measured parameters. 


\section{Solution}

A new method has been developed, the essence of which consists in diagnosing FF leakage during SRP operation, which involves measuring the pressure on the well flow line and at two points of TS of the well, one of which is located at the TS orifice, and the second one lower at a distance of half the length of the cylinder of the pump being used, the FF leakage from downhole pumping equipment being calculated by the following algorithm:

$$
\begin{aligned}
Q_{a} & \left.=K \propto F \cdot \sqrt{\frac{P_{1}-P_{5}}{\rho_{f}}}\right) \cdot K_{c} \\
& =\frac{\Delta P_{l}}{h g}=\frac{\left(P_{2}-P_{1}\right)_{u}}{h g} \\
\Delta h & =\frac{\Delta P_{l}}{\rho_{f} g}=\frac{\left(P_{2}-P_{1}\right)_{l}}{\rho_{f} g} \\
V_{f} & =F_{c} \cdot l \cdot \beta \\
Q_{t} & =1440 V_{f} n \\
Q_{l} & =\frac{Q_{t}-Q_{a}}{Q_{t}} \cdot 100 \%
\end{aligned}
$$

where $V_{f}$ is the volume of FF in the cylinder at the initial upward movement of the plunger, $\mathrm{m}^{3} ; \mathrm{K}_{c}$ is the conversion factor converting FF flow rate from $\mathrm{m}^{3} / \mathrm{s}$ to $\mathrm{m}^{3} /$ day; $Q_{t}, Q_{a}$ is the theoretical and actual FF flow rate, $\mathrm{m}^{3} / \mathrm{day} ; F$ is the crosssectional area of the flow line check valve, $\mathrm{m}^{2} ; \mathrm{K}$ is the empirical coefficient, determined empirically (experimentally), taking into account the discrepancy between the calculated and actual flow; $\mathrm{P}_{5}$ is the well flow line pressure, $\mathrm{Pa} ; \mathrm{P}_{1}, \mathrm{P}_{2}$ is the pressure at the wellhead and at a point located below the tapping point $\mathrm{P}_{1}$ at a distance corresponding to half the height of the cylinder of the pump used, $\mathrm{m}$; $\propto$ is the the flow coefficient determined experimentally (from the diagram) depending on the value of $\frac{D_{n}^{2}}{D^{2}}$ and the Reynolds number Re (see Figure 2, where $D_{n}$ is the nominal size of the check valve, $\mathrm{m} ; F_{c}$ is the crosssectional area of the cylinder, $\mathrm{m}^{2} ; D$ is the TS flow line diameter, $\mathrm{m}) ; \beta$ is the volumetric efficiency of the pump cylinder, fractional; $l$ is the pump cylinder length, $\mathrm{m} ; \Delta h$ is the FF level between the pressure tap gauges $P_{2}$ and $P_{1}$ in the lower position of the plunger, $\mathrm{m} ; \Delta P_{l}, \Delta P_{u}$ is the differential pressures between $P_{2}$ and $P_{1}$ in the lower and upper positions of the pump plunger, $\mathrm{Pa} ; \rho_{f}$ is the FF density, $\mathrm{kg} / \mathrm{m}^{3} ; h$ is the distance between gauges 1 and $2, \mathrm{~m} ; n$ is the number of swings of the walking beam, $\mathrm{min}^{-}$ ${ }^{1} ; g$ is the gravitational acceleration, $\mathrm{m} / \mathrm{s}^{2}$.

We also propose a device for implementing the method. The device includes pressure gauges installed on the TS flow line and at two points of the TS of the well, one of which is located at the TS orifice, and the second one below at a distance of half the length of the cylinder of the pump used, a liquid level gauge, a computation and control unit (Figure 1).

The advantages of the proposed method over those known in this field are measurement accuracy, simplicity, as its implementation does not require complex devices, calculation speed and automatic measurement of the well flow rate and FF leakage during SRPU operation, which makes it possible to quickly detect the malfunction and manage the oil production process.

In the course of the accumulated experience, it was established that the cylinder of a deep-well pump is always filled to at least half its length, and the difference in pressure measured at the two indicated points is always proportional to the FF filling level of the pump cylinder.

Figure 1 shows the basic schematic of the device for implementing the method, where: 1 - gauge at the TS orifice; 2 gauge at the TS below gauge 1, at the distance of half the length of the cylinder of the pump used; 3 - differential manometer; 4 well flow line; 5 - well flow line pressure gauge; 6 - differential manometer; 7 - liquid level gauge in the production (casing) string; 8 - converter; 9 - computation and control unit; 10 polished rod string; 11 - production casing; 12 - TS.

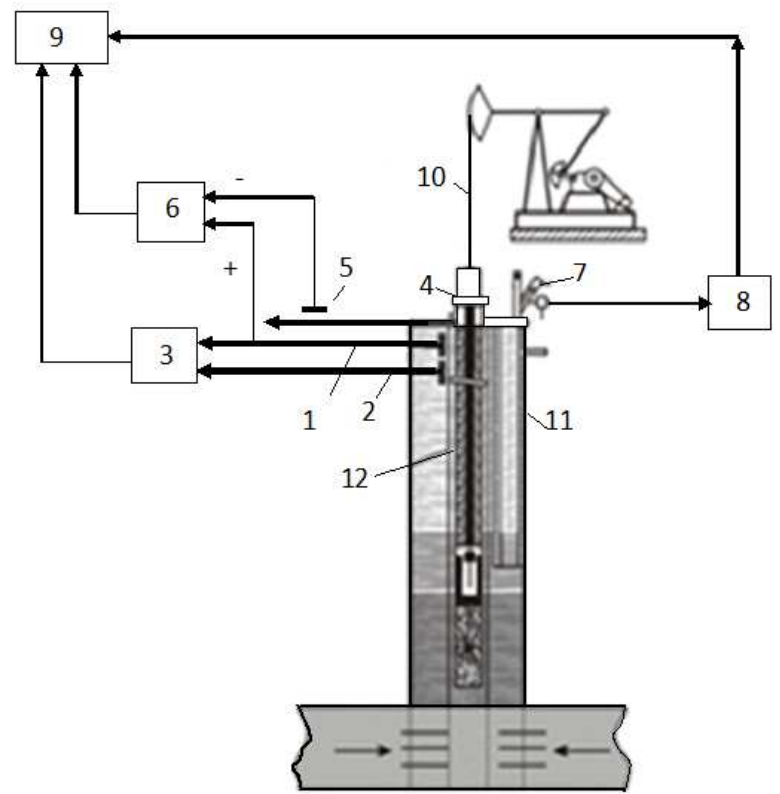

Figure 1. Basic schematic of the system for diagnosing FF leakage during SRPU operation.

The method is implemented as follows.

The differential pressure is measured between pressure gauges 1 and 2 installed at the TS orifice at a distance of half the length $l$ of the cylinder of the pump used in the given well: $h=1 / 2 l$. Gauge 5 measures the pressure on the flow line 4 of the well. The outputs of the pressure gauges are connected to the chambers of differential manometers 3 and 6 of the SAPPHIR type, the outputs of which are connected to calculation and control unit 9. The lower gauge, 2, is connected to the positive chamber of differential manometer 3 , and the upper one - to the negative chamber of differential manometer 3 and the positive chamber of differential manometer 6 . The outputs of gauge 5 are connected to the negative chamber of differential manometer 6 .

An example of the method implementation.

1. inner diameter of TS $-D_{\mathrm{t}}=0.5 \mathrm{~m}$;

2. pump cylinder diameter $-D_{c}=0.43 \mathrm{~m}$;

3. pump rod diameter $-D_{r}=0.02 \mathrm{~m}$;

4. differential pressure between gauges 1 and 2 at the 
lower position of the pump plunger $\Delta \mathrm{P}_{l}=2793 \mathrm{~Pa}$;

5. differential pressure between gauges 1 and 2 in the upper position of the pump plunger $\Delta \mathrm{P}_{u}=8820 \mathrm{~Pa}$;

6. fluid level measured from the differential pressure $\left(\Delta \mathrm{P}_{l}=2793 \mathrm{~Pa}\right)-\Delta h_{\mathrm{t}}=0.3 \mathrm{~m}$;

7. density of the mixed fluid (at $\left.\Delta \mathrm{P}_{u}=8820 \mathrm{~Pa}\right)-\rho_{f}=$ $900 \mathrm{~kg} / \mathrm{m}^{3}$;

8. pump cylinder length $-l_{c}=2 \mathrm{~m}$;

9. cross-sectional area of TS $-F_{\mathrm{t}}=1,884 \cdot 10^{-3} \mathrm{~m}^{2}$

10. cross-sectional area of the pump cylinder $-F_{c}=1.451$. $10^{-3} \mathrm{~m}^{2}$

11. cross-sectional area of the $\operatorname{rod}-F_{r}=3.14 \cdot 10^{-4} \mathrm{~m}^{2}$; 12. gravitational acceleration $\sim g=9.80 \mathrm{~m} / \mathrm{s}^{2}$

The volumetric efficiency of the pump cylinder $\beta$ :

$$
\begin{gathered}
\rho_{f}=\frac{\Delta P_{u}}{g h}=\frac{8820}{9.80 \cdot 1.0}=900 \mathrm{~km} / \mathrm{m}^{3} \\
\Delta h=\frac{\Delta P_{l}}{\rho_{f} g}=\frac{3724}{900 \cdot 9.80}=0.4 \mathrm{~m} \\
\beta=\frac{\frac{1}{2} \cdot 2+0.3\left(\frac{1.884 \cdot 10^{-3}-3.14 \cdot 10^{-4}}{1.451 \cdot 10^{-3}}\right)}{2} \cdot 100 \%=72.71 \%
\end{gathered}
$$

1. volume of FF in the cylinder at the start of the upward movement of the plunger $-\mathrm{V}_{\mathrm{f}}=\mathrm{F}_{\mathrm{c}} 1 \beta=1.451 \cdot 10^{-3} \cdot 2$. $0.7271 \cdot 10^{-4}=2.11 \cdot 10^{-3} \mathrm{~m}^{3}$

2. theoretical production rate of $F F-Q_{t}=1440 \cdot 2.11$. $10^{-3} \cdot 12=36.46 \frac{\mathrm{m}^{3}}{\mathrm{day}}$

3. cross-sectional area of the check valve $-\mathrm{F}=1.766 \mathrm{~m}^{2}$;

4. linear flow velocity of FF through the check valve $\vartheta=\frac{\mathrm{Q}_{\mathrm{t}}}{\mathrm{FK}_{\mathrm{f}}}=\frac{36.46}{1.766 \cdot 8.64}=2.391 \frac{\mathrm{m}}{\mathrm{s}}$;

5. kinematic viscosity $\mathrm{FF}-v=0.05 \mathrm{~cm}^{2} / \mathrm{s}$;

6. differential pressure in the check valve between $P_{1}$ and $\mathrm{P}_{3}$ in the upper position of the plunger $-\Delta \mathrm{P}_{\mathrm{v}}=3$. $10^{5} \mathrm{~Pa}$;

7. flow coefficient $-\alpha=0.7$, determined from the diagram shown in Figure 2, with the value $\mathrm{m}=\mathrm{d}_{\mathrm{v}}{ }^{2} / \mathrm{D}_{\mathrm{f}}{ }^{2}=0.09 \quad$ (where $\mathrm{d}_{\mathrm{v}}$ is the cross-sectional diameter of the check valve, and $D_{f}$ is the well flow line diameter), and the Reynolds number $\mathrm{R}=\frac{\vartheta \cdot \mathrm{d}_{\mathrm{v}}}{v}=$ $\frac{239.1 \cdot 1.5}{0.05}=8970$

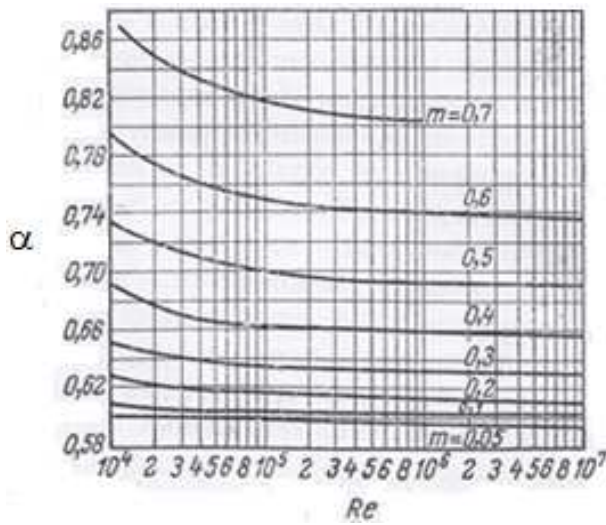

Figure 2. Diagrams for determining the value of the flow coefficient $\alpha$.
1. the numerical value of the empirical coefficient $\mathrm{K}$ is determined as follows:

2. using an automated group metering unit [12], the actual FF flow rate is determined -

$$
\mathrm{Q}_{\mathrm{a}}=29.9 \mathrm{~m}^{3} / \text { day }=3.46 \cdot 10^{-4} \mathrm{~m}^{3} / \mathrm{s} ;
$$

3. the differential pressure in the check valve installed on the flow line is measured $-\Delta \mathrm{P}=\mathrm{P}_{1}-\mathrm{P}_{3}=2.94$. $10^{5} \mathrm{~Pa}$;

4. substituting the found values of $\mathrm{Q}_{\mathrm{a}}, \Delta \mathrm{P}, \mathrm{F}, \rho_{\mathrm{f}}, \alpha$ and $\mathrm{K}_{\mathrm{c}}$ into formula (1), the value of $K$ is calculated:

$$
\mathrm{K}=\frac{\mathrm{Q}_{\mathrm{a}}}{\alpha \cdot \mathrm{F} \sqrt{\frac{\mathrm{P}_{1}-\mathrm{P}_{3}}{\rho_{\mathrm{f}}}}}=\frac{3.46 \cdot 10^{-4}}{0.608 \cdot 1.766 \sqrt{\frac{2.94 \cdot 10^{3}}{900}}}=0.1783
$$

Substituting the found values of the flow coefficient and the empirical coefficient $K$ into formula (1), we obtain:

$$
\begin{aligned}
\mathrm{Q}_{a} & =0.1783 \cdot 0.608 \cdot 8.64 \cdot 10^{4} \cdot \mathrm{F} \sqrt{\frac{\mathrm{P}_{1}-\mathrm{P}_{3}}{\rho_{\mathrm{f}}}} \\
& =9.366 \cdot 10^{3} \cdot \mathrm{F} \sqrt{\frac{\mathrm{P}_{1}-\mathrm{P}_{3}}{\rho_{\mathrm{f}}}}
\end{aligned}
$$

Thus, obtained working formula (7) allows calculating the actual flow rate of $F F$ for any values of $P_{1}-P_{3}, \rho_{f}$ and $F$.

With the values of $Q_{t}$ and $Q_{a}$ known, the value of $F F$ leakage during SRPU operation is determined:

$$
Q_{1}=Q_{t}-Q_{a}=36.46-29.9=6.56 \frac{\mathrm{m}^{3}}{\text { day }^{\prime}}
$$

i.e. the leakage is

$$
\mathrm{Q}_{\mathrm{l}}(\%)=\frac{\mathrm{Q}_{\mathrm{t}}-\mathrm{Q}_{a}}{\mathrm{Q}_{\mathrm{t}}}=18 \%
$$

Thus, as the sample calculation shows, the FF leakage during SRPU operation is $18 \%$ and proposed formulas (1)-(7) are correct.

\section{Conclusions}

A new method for diagnosing formation fluid leakage during SRP operation and a device for its implementation have been proposed. Unlike existing methods, in which leakage is determined by (the "cylinder-plunger pair" clearance, valves, etc.) dynamometer cards and piezograms that have low accuracy, the proposed method allows more accurate and reliable automated determination of the amount of leakage. For this purpose, the pressure is automatically measured on the flow line of the well and at two points of the TS of the well. New algorithms for calculating the leakage and a method for determining the value of the flow rate and the empirical coefficient, which are included in the mathematical expression for determining the actual value of oil output, have been proposed. The correctness of the algorithms has been confirmed by the sample calculation 
given in the paper.

\section{References}

[1] Kovshov V. D., Sidorov M. Y., Svetlanova S. B. Dynamometry, modeling and diagnostics of sucker rod pumping units. Izvestiya Vysshikh Uchebnykh Zavedeniy. Neft' i Gaz. 2011, No. 3. (in Russian).

[2] Muravyev V. M. Operation of oil and gas wells. M. Nedra, 1978. (in Russian).

[3] Eurasian patent No 023666 issued 30.10.2015. Method of diagnostics of deep-well pumps// Aliev T. A., Rzayev Ab. H., Guluyev G. A., Rzayev A. G.//

[4] Adonin A. N. Oil production by sucker rod pumps, M.: Nedra, 1978,448 p. (in Russian).

[5] Bakhtizin R. N., Urazakov K. R., Latypov B. M., Ishmukhametov B. Kh. Fluid leakage in a sucker rod pump with regular microrelief on the surface of the plunger, Razrabotka Neftyanykh i Gazovykh Mestorozhdeniy, 2016, Vol 14, No 4, pp. 33-39. (in Russian).

[6] Kruman B. B. Practice of operation and survey of pumping wells, M.: Nedra, 1964, 204 p. (in Russian).

[7] Isakovich R. Y., Ponadko V. Y. Control and automation of oil and gas production, M.: Nedra, 1985, 351 p. (in Russian).
[8] Eurasian patent No 025383 issued 30.12.2016. Method of management of deep-well pump feeding process and the device for its implementation// Aliev T. A., Rzayev Ab. H., Guluyev G. A.//

[9] Mishenko I. T. Downhole oil production, M.: Neft' i Gaz, 2003, 816 p. (in Russian).

[10] Abbasov E. M., Kazimov Sh. P., Abdullayeva N. R., Hajikerimova L. G. Fluid leakage in a downhole sucker rod pump, Neftyanoye Khozyaystvo, 2019, No 4, pp. 87-89. (in Russian).

[11] Mineyev B. P. On ways to increase the delivery rate of sucker rod pumps. http://www/oilgasindustry.ru/2012 (in Russian).

[12] Rzayev Ab. G., Rasulov S. R., Isayev M. M., Asadova R. Sh. A measuring system for determining the filtration characteristics of an oil reservoir, Izmeritelnaya Tekhnika, Moscow, 2019, No 1, pp. 34-38 (in Russian).

[13] Eurasian patent No 020663 issued 30.12.2014. Method of measurement of oil well flow rate// Aliev T. A., Rzayev Ab. G., Guluyev G. A., Rzayev As. G. Yusifov I. B//.

[14] Rzayev Ab. G., Rasulov S. R., Babayev S. F. Automated regulation of submersible pump delivery, Transport i Khraneniye Nefteproduktov i Uglevodorodnogo Syrya, Moscow, 2018, No 4, pp. 43-45 (in Russian).

[15] Eurasian patent No 036115 issued 30.09.2020, A method of oil production process control// Aliev T. A., Rzayev Ab. G., Rasulov S. R.// 